\title{
Geotechnical modeling of fractures and cavities that are associated with geotechnical engineering problems in Kuala Lumpur limestone, Malaysia.
}

\begin{abstract}
This study presents a modified geotechnical model of subsurface cavities and fractures that are associated with foundation and pilling problems. The topographical model was used to automatically extract minimum surface curvature, slope, and pits. The image processing shows that more than fourteen regional faults, trending NE, SW, and WNW affect the Kuala Lumpur limestone bedrock and the surface topography from South to North. These fractures often show higher probability of piling and constructions problems. The faults are tensional, low lying, and wrench of length 10-20km. Opencast ex-mining pond floors (bathymetry) are good indicators of subsurface fractures and cavities that affect the limestone bedrock. The LANDSAT image (band one) shows that the fractures of opencast ex-mining pond floors have the same trend as the regional faults. These techniques can help geotechnical engineers to predict subsurface fractures and cavities, especially in areas adjacent to ex-mining ponds. In brief, most of the subsurface cavities and ex-mining ponds, for example the Phong Fatt pond, are located on and along fault zones.
\end{abstract}

Keyword: Remote sensing; Geotechnical modeling; Fractures; Cavities 